6. Wake, K., et al. 1989. Cell biology and kinetics of Kupffer cells in the liver. Int. Rev. Cytol. 118:173-229.

7. Goerdt, S., and Orfanos, C.E. 1999. Other functions, other genes: alternative activation of antigenpresenting cells. Immunity. 10:137-142.

8. Knolle, P.A., and Gerken, G. 2000. Local control of the immune response in the liver. Immunol. Rev. 174:21-34.

9. Vazquez-Torres, A., et al. 2004. Toll-like receptor 4 dependence of innate and adaptive immunity to Salmonella: importance of the Kupffer cell network. J. Immunol. 172:6202-6208.

10. Sun, Z., et al. 2003. Hepatic allograft-derived Kupffer cells regulate $\mathrm{T}$ cell response in rats. Liver. Transpl. 9:489-497.

11. Iredale, J.P., et al. 1998. Mechanisms of spontaneous resolution of rat liver fibrosis. Hepatic stellate cell apoptosis and reduced hepatic expression of metalloproteinase inhibitors. J. Clin. Invest. 102:538-549.

12. Issa, R., et al. 2004. Spontaneous recovery from micronodular cirrhosis: evidence for incomplete resolution associated with matrix cross-linking. Gastroenterology. 126:1795-1808.

13. Murphy, F.R., et al. 2002. Inhibition of apoptosis of activated hepatic stellate cells by tissue inhibitor of metalloproteinase- 1 is mediated via effects on matrix metalloproteinase inhibition: implications for reversibility of liver fibrosis. J. Biol. Chem. 277:11069-11076

14. Parsons, C.J., et al. 2004. Antifibrotic effects of a tissue inhibitor of metalloproteinase- 1 antibody on established liver fibrosis in rats. Hepatology. 40:1106-1115.

15. Duffield, J.S. 2003. The inflammatory macrophage: a story of Jekyll and Hyde. Clin. Sci. 104:27-38.

16. Gale, R.P., Sparkes, R.S., and Golde, D.W. 1978 Bone marrow origin of hepatic macrophages (Kupffer cells) in humans. Science. 201:937-938.

17. Matsuoka, M. and Tsukamoto, H. 1990. Stimulation of hepatic lipocyte collagen production by Kupffer cell-derived transforming growth factor beta: implication for a pathogenetic role in alcoholic liver fibrogenesis. Hepatology. 11:599-605

18. Friedman, S.L., and Arthur, M.J. 1989. Activation of cultured rat hepatic lipocytes by Kupffer cell conditioned medium. Direct enhancement of matrix synthesis and stimulation of cell proliferation via induction of platelet-derived growth factor receptors. J. Clin. Invest. 84:1780-1785.
19. Fischer, R., Cariers, A., Reinehr, R., and Haussinger, D. 2002. Caspase 9-dependent killing of hepatic stellate cells by activated Kupffer cells. Gastroenterology. 123:845-861.

20. Pikarsky, E., et al. 2004. NF-kappaB functions as a tumour promoter in inflammation-associated cancer. Nature. 431:461-466.

21. Knittel, T., et al. 1999. Expression patterns of matrix metalloproteinases and their inhibitors in parenchymal and non-parenchymal cells of rat liver: regulation by TNF-alpha and TGF-beta1. J. Hepatol. 30:48-60.

22. Han, Y.P., et al. 2004. Essential role of matrix metalloproteinases in interleukin-1-induced myofibroblastic activation of hepatic stellate cell in collagen. J. Biol. Chem. 279:4820-4828.

23. Issa, R., et al. 2003. Mutation in collagen-1 that confers resistance to the action of collagenase results in failure of recovery from $\mathrm{CCl} 4$-induced liver fibrosis, persistence of activated hepatic stellate cells, and diminished hepatocyte regeneration. FASEB J. 17:47-49.

24. Friedman, S.L. 2000. Molecular regulation of hepatic fibrosis, an integrated cellular response to tissue injury. J. Biol. Chem. 275:2247-2250.

\title{
Stay tuned to PXR: an orphan actor that may not be D-structive only to bone
}

\author{
Michael F. Holick
}

Vitamin D, Skin, and Bone Research Laboratory, Section of Endocrinology, Diabetes, and Nutrition, Department of Medicine, Boston University School of Medicine, Boston, Massachusetts, USA.

\begin{abstract}
Pregnane $X$ receptor (PXR) plays an important role in detoxifying xenobiotics and drugs. In this issue of the JCI, Pascussi et al. (see the related article beginning on page 177) provide convincing evidence that PXR can also induce vitamin $\mathrm{D}$ deficiency and bone disease because of its ability to cross-talk with the vitamin D-responsive gene that catabolizes 25-hydroxyvitamin $\mathrm{D}$ and 1,25-dihydroxyvitamin $\mathrm{D}$. This cross-talk behavior has important health ramifications and can be mitigated through the identification and treatment of PXR-induced vitamin D deficiency.
\end{abstract}

\section{Historical perspective}

In 1967 Schmid (1) reported an association between osteomalacia and antiepileptic drug therapy. This was confirmed by Dent et al. (2), who noted that osteomalacia and rickets were common in patients on longterm antiepileptic drug therapy, especially those who had been institutionalized and treated with multiple drugs to control their seizure disorder. Since these initial observations were made, there have been a multitude of reports of abnormalities in calcium,

Nonstandard abbreviations used: CYP24, 25-hydroxyvitamin D-24-hydroxylase; PXR, pregnane X receptor; $R X R$, retinoic acid $X$ receptor; VDR, vitamin $D$ receptor; VDRE, vitamin D-responsive element.

Conflict of interest: The author has declared that no conflict of interest exists.

Citation for this article: J. Clin. Invest. 115:32-34 (2005). doi:10.1172/JCI200523995. vitamin $\mathrm{D}$, and bone metabolism in subjects chronically treated not only with antiepileptic drugs but also with glucocorticoids, rifampin, and antiretroviral drugs (3-6). The disturbances observed in antiepileptic drug-treated patients were noted to be very similar to those of patients with vitamin D deficiency. More than $50 \%$ of children and adults receiving chronic antiepileptic drug therapy are at risk for developing abnormalities in calcium, vitamin $\mathrm{D}$, and bone metabolism (3). However, cardiac patients who had been treated with conventional doses of phenytoin for control of arrhythmias were found to be free of these abnormalities (7).

Antiepileptic drug-induced alterations in calcium and bone metabolism can include biochemical abnormalities such as hypocalcemia, hypophosphatemia, and elevated serum concentrations of alkaline phosphatase, parathyroid hormone, and 1,25-dihydroxyvitamin $\mathrm{D}\left[1,25(\mathrm{OH})_{2} \mathrm{D}\right]$. The biochemical hallmark for this disorder is reduced serum concentration of 25-hydroxyvitamin D [25(OH)D], the major circulating form, which is a barometer for a person's vitamin D status (8). There is an associated decrease in intestinal calcium absorption, a reduction in urinary calcium excretion, and an increase in bone turnover, as evidenced by increases in osteocalcin, bone-specific alkaline phosphatase, procollagen type $1 \mathrm{C}$-terminal extension peptide, and bone resorption markers including human collagen type $1 \mathrm{C}$-terminal peptide and total free deoxypyridinoline. The bone condition most often associated with chronic antiepileptic drug treatment is reduced bone mineral density and cortical bone loss. Rickets and, according to histologic evidence, osteomalacia indicating a defect in bone mineralization are also accompanying problems (3).

\section{Mechanism for drug-induced disorders of bone metabolism}

A variety of mechanisms have been proposed for the antiepileptic drug-induced disorders in calcium and bone metabolism. Gascon-Barré et al. (3-5) and Hahn et 


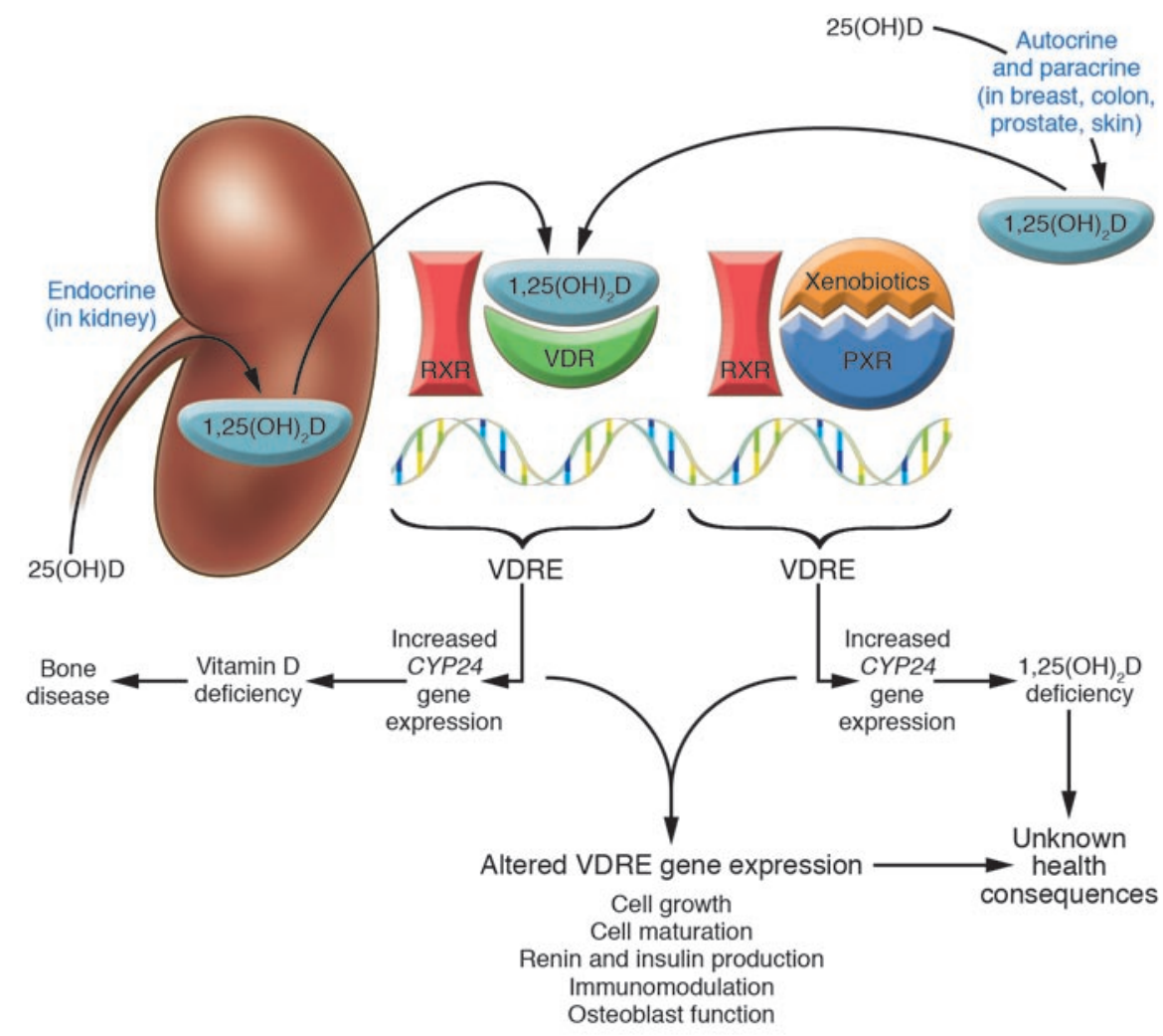

Figure 1

A schematic illustrating how xenobiotics and drugs that activate PXR can disrupt vitamin $\mathrm{D}$ metabolism and vitamin $\mathrm{D}$ function. The kidney is responsible for converting $25(\mathrm{OH}) \mathrm{D}$ to $1,25(\mathrm{OH})_{2} \mathrm{D}$. Once formed, $1,25(\mathrm{OH})_{2} \mathrm{D}$ enters the blood and travels to its calcium-regulating target tissues, where it interacts with its specific nuclear VDR. This complex binds RXR, and the resulting heterodimeric complex binds to specific VDREs in the DNA, leading to regulation of gene expression responsible for calcium and bone metabolism. 25(OH)D can also be metabolized in a wide variety of tissues, including colon, prostate, breast, and skin, where it acts either as an autocrine or paracrine hormone to regulate cell growth and carry out other physiologic functions. Xenobiotics and drugs that activate PXR bind RXR. This heterodimeric complex is recognized by the VDRE of CYP24, which is responsible for the destruction of $1,25(\mathrm{OH})_{2} \mathrm{D}$ into a water-soluble, inactive metabolite. The activated PXR-RXR complex may also be able to alter other VDREs that have wide-ranging biologic functions in cell growth and maturation, immunomodulation, renin and insulin production, and osteoblast function. Understanding of the consequences of this potential interaction and alteration of VDRE gene expression on noncalcemic functions of vitamin $D$ requires further investigation.

al. (6) suggested that alterations in vitamin $\mathrm{D}$ metabolism are mainly a consequence of induction of destructive hepatic P450 enzyme(s) by phenobarbital, phenytoin, and carbamazepine. This induction was thought to lead to an increase in vitamin D turnover, including catabolism. Indeed, it was demonstrated that phenobarbital treatment increased hepatic endobiotic/ xenobiotic metabolizing enzyme capacity, which increased not only the metabolism of vitamin $\mathrm{D}$ to $25(\mathrm{OH}) \mathrm{D}$ in the liver but also its turnover - ultimately leading to vitamin $\mathrm{D}$ deficiency. This explains why it is often observed that patients initially taking an antiepileptic drug have increased circulating concentrations of $25(\mathrm{OH}) \mathrm{D}$ followed by a rapid decrease that leads to vitamin $\mathrm{D}$ deficiency.

Hahn et al. (6) noted that rats that initially received phenobarbital had increased blood levels not only of 25(OH)D but also of 24, 25dihydroxyvitamin $\mathrm{D}_{3}\left[24,25(\mathrm{OH})_{2} \mathrm{D}_{3}\right]$, while the $1,25(\mathrm{OH})_{2} \mathrm{D}_{3}$ levels were unchanged. However, after 21 days of treatment, both $25(\mathrm{OH}) \mathrm{D}_{3}$ and $24,25(\mathrm{OH})_{2} \mathrm{D}_{3}$ concentrations and intestinal calcium absorption were significantly decreased, while $1,25(\mathrm{OH})_{2} \mathrm{D}_{3}$ concentrations increased by $80 \%$.

Pascussi et al. (9) now provide new insight into how antiepileptic drugs as well as other xenobiotic drugs, including rifampin, glucocorticoids, and antiretroviral drugs, induce vitamin $\mathrm{D}$ deficiency and decrease bone mineral density. The authors recognized that a common property of these medications is the induction of hepatic cytochrome P450s involved in drug metabolism, including CYP2B and CYP3A. Since pregnane $\mathrm{X}$ receptor (PXR) induced both CYP2 and CYP3 and PXR shared approximately $60 \%$ homology of the amino acid sequence in the DNA binding domain of the vitamin $\mathrm{D}$ receptor (VDR), they reasoned that PXR could act on the vitamin D-responsive element (VDRE) motifs on 25-hydroxyvitamin D-24-hydroxylase (CYP24), which is responsible for the catabolism of $25(\mathrm{OH}) \mathrm{D}$ and $1,25(\mathrm{OH})_{2} \mathrm{D}(10,11)$.

Although $25(\mathrm{OH}) \mathrm{D}$ is the major circulating form of vitamin $\mathrm{D}$, it must be converted in the kidney to $1,25(\mathrm{OH})_{2} \mathrm{D}$ before it is functional in target tissues, including intestine, bone, and kidney $(8,11)$ (Figure 1). 1,25( $\mathrm{OH})_{2} \mathrm{D}$ interacts with its specific VDR, which then forms a heterodimeric complex with retinoic acid $\mathrm{X}$ receptor (RXR). This complex binds to specific VDREs to induce gene expression for its various physiologic functions on calcium and bone metabolism. Once it has accomplished its anabolic function(s), $1,25(\mathrm{OH})_{2} \mathrm{D}$ induces its own destruction through the VDR-RXR nuclear mechanism by enhancing the expression of CYP24. The hydroxylation of $1,25(\mathrm{OH})_{2} \mathrm{D}$ on carbon 24 initiates a cascade of hydroxylation and oxidation events leading to the formation of the water-soluble and biologically inactive calcitroic acid $(10,11)$.

Pascussi et al. (9) also recognized that the ligand-binding domains of the VDR and PXR share 37\% identity and that lithocholic acid and derivatives are activators for both VDR and PXR. Furthermore, PXR has a heterodimeric partner, $\mathrm{RXR} \alpha$, similar to VDR. Thus, the authors speculated that functional nuclear receptor cross-talk might cause PXR activators to interfere with VDR-controlled CYP24.

Pascussi et al. (9) conducted a series of elegant in vitro and in vivo studies that provide convincing evidence that a drug that can activate PXR is likely to enhance CYP24 expression and the catabolism of $25(\mathrm{OH}) \mathrm{D}$, leading to vitamin $\mathrm{D}$ deficiency. These include a wide variety of pharmaceutical agents, including antiepileptic drugs, taxol, rifampin, and human immunodeficiency virus protease inhibitors such as ritonavir and saquinavir, as well as the herbal antidepressant St. John's wort. 


\section{PXR: cross-talk causes vitamin $\mathrm{D}$ deficiency}

This orphan actor (PXR) is responsible for the regulation of enzymes and transporters that help the body rid itself of potential toxic and offensive chemicals. Man-made drugs, which appear as foreign substances, are an ideal target for PXR. The fact that once activated, the PXR-RXR complex can substitute for activated VDR-RXR explains why drugs from diverse families can have effects on calcium, vitamin $\mathrm{D}$, and bone metabolism. The cross-talk between PXR and VDR has important implications for bone health. It is likely that other families of drugs also are activators of PXR and may play a role in enhancing vitamin $\mathrm{D}$ catabolism.

It is now recognized that most of the population in the United States is at risk of vitamin $\mathrm{D}$ deficiency $(8,12,13)$. Knowledge of the fact that xenobiotics and drugs can enhance the destruction of $25(\mathrm{OH}) \mathrm{D}$ and $1,25(\mathrm{OH})_{2} \mathrm{D}$ should heighten physicians' awareness that patients on almost any medication or herbal supplement could potentially become vitamin $\mathrm{D}$ deficient because of the pleiotropic effect of PXR activation. The good news is that vitamin D deficiency is both easy to monitor and equally easy to treat. A regimen of 50,000 IU of vitamin $\mathrm{D}_{2}$ once a week for 8 weeks, followed by 50,000 IU of vitamin $\mathrm{D}_{2}$ twice a month is often adequate (13). Patients should maintain $25(\mathrm{OH}) \mathrm{D}$ at a level of at least $30-50 \mathrm{ng} / \mathrm{ml}$ to overcome the destructive effect of PXR on vitamin $\mathrm{D}$ catabolism.

This observation has far-reaching ramifications for vitamin $\mathrm{D}$ beyond bone metabolism. It will be interesting to see whether the PXR-VDR cross-talk affects other VDR-responsive genes. It is now recognized that $1,25(\mathrm{OH})_{2} \mathrm{D}$, through its interaction with VDR, has a wide variety of biologic effects that not only control calcium metabolism but are also important for osteoblast function, regulating the immune system as well as renin and insulin production $(16,17)$ and controlling the expression of genes that modulate cell growth, including those responsible for apoptosis, cell cycle arrest, and differentiation $(8,15)$. Thus, it is reasonable to speculate that xenobiotics and drugs causing vitamin $\mathrm{D}$ deficiency can increase risk of type 1 diabetes, multiple sclerosis, rheumatoid arthritis, hypertension, cardiovascular heart disease, and common cancers $(8,14-18)$ - diseases that have been linked to vitamin D deficiency (8).
It is also likely that xenobiotics and drugs interact with the PXR system in a selective manner, resulting in organ-specific alterations of genes that are regulated by $1,25(\mathrm{OH})_{2} \mathrm{D}$. For example, glucocorticoids are known to cause bone demineralization. There have been a variety of mechanisms proposed, including alterations in intestinal calcium absorption and osteoblast bone formation, two functions that are regulated by $1,25(\mathrm{OH})_{2} \mathrm{D}$. It is possible that when PXR is activated by prednisone, it could cause a conformational change different from that occurring when PXR binds an antiepileptic drug, resulting in a different interaction with the VDR-responsive genes in osteoblasts. It is also possible that some xenobiotics, through this PXR-VDR crosstalk mechanism described by Pascussi et al. (9), could cause local tissue vitamin D deficiency by selectively upregulating CYP24. It is conceivable that a drug targeted to the prostate might not only have the desired effect on prostate cell growth, but also could induce the PXR transactivation of CYP24 to locally decrease cellular levels of $1,25(\mathrm{OH})_{2} \mathrm{D}$. This has interesting implications now the prostate, colon, and breast all are believed to have the enzymatic machinery (CYP27B2) to increase the local production of $1,25(\mathrm{OH})_{2} \mathrm{D}$. Once produced, $1,25(\mathrm{OH})_{2} \mathrm{D}$ locally helps regulate cell growth by interaction with VDR through transactivation of a variety of genes that regulate cell growth and differentiation. Local tissue induction of CYP24 by activated PXR could negate this effect by rapidly destroying any $1,25(\mathrm{OH})_{2} \mathrm{D}$ that is made. This was demonstrated in a prostate cancer line - DU145 - that had marked increase in CYP24 activity $(19,20)$. Unlike other prostate cancer cell lines (PC3 and LNCaP), these cells do not respond well to the antiproliferative effect of $25(\mathrm{OH}) \mathrm{D}$, because the markedly enhanced CYP24 expression rapidly destroys any $1,25(\mathrm{OH})_{2} \mathrm{D}$ that is produced in the cells.

The message is simple. It is likely that the drugs described by the authors are not the only ones that affect the PXR-VDR crosstalk and that further scrutiny will reveal that several other families of drugs and xenobiotics can have a similar effect. Thus, the vitamin D status of patients on almost any type of medication should be monitored.

Address correspondence to: Michael F. Holick, Boston University Medical Center, Endocrine Section, Department of Medicine, Vitamin D, Skin and Bone Research
Laboratory, 715 Albany Street, M-1013, Boston, Massachusetts 02118, USA. Phone: (617) 638-4545; Fax: (617) 638-8882; E-mail:mfholick@bu.edu.

1. Schmid, F. 1967. Osteophthien bei antiepileptischer Dauerbehandlung. Fortschr. Med. 38:381-382.

2. Dent, C.E., Richens, A., Rowe, D.J.F., and Stamp, T.C.B. 1970. Osteomalacia with long-term anticonvulsant therapy in epilepsy. Br. Med.J. 4:69-72.

3. Gascon-Barré, M. 2004. Antiepileptic drugs and bone health. In Nutrition and bone health. B. DawsonHughes and M.F. Holick, editors. Humana Press. Totowa, New Jersey, USA. 647-666.

4. Gascon-Barré, M., and Gamache, M. 1991. Contribution of the biliary pathway to the homeostasis of vitamin $\mathrm{D}_{3}$ and 1,25-dihydroxyvitamin $\mathrm{D}_{3}$. Endocrinology. 129:2335-2344.

5. Gascon-Barré, M., Vallieres, S., and Huet, P.M. 1986. Influence of phenobarbital on the hepatic handling of $\left[{ }^{3} \mathrm{H}\right]$ vitamin $\mathrm{D}_{3}$ in the dog. Am. J. Physiol. 251:G627-G635.

6. Hahn, T.J., Birge, S.J., Scharp, C.R., and Avioli, L.V. 1972. Phenobarbital-induced alterations in vitamin D metabolism. J. Clin. Invest. 51:741-748.

7. Wark, J.D., et al. 1979. Chronic diphenylhydantoin therapy does not reduce plasma 25 -hydroxyvitamin D. Clin. Endocrinol. 11:267-274.

8. Holick, M.F. 2004. Vitamin D: importance in the prevention of cancers, type 1 diabetes, heart disease, and osteoporosis. Am. J. Clin. Nutr. 79:362-371.

9. Pascussi, J.M., et al. 2005. Possible involvement of pregnane X receptor-enhanced CYP24 expression in drug-induced osteomalacia. J. Clin. Invest. 115:177-186. doi:10.1172/JCI200521773.

10. Chen, K.S., and DeLuca, H.F. 1995. Cloning of the human 1 alpha,25-dihydroxyvitamin $\mathrm{D}_{3}$ 24-hydroxylase gene promoter and identification of two vitamin D-responsive elements. Biochim. Biophys. Acta. 1263:1-9.

11. Omdahl, J.L., Bobrovinkova, E.A., Choe, S., Dwivedi, P.P., and May, B.K. 2001. Overview of regulatory cytochrome $\mathrm{P} 450$ enzymes of the vitamin D pathway. Steroids. 66:381-389.

12. Lips, P., et al. 2001. A global study of vitamin D status and parathyroid function in postmenopausal women with osteoporosis: baseline data from the multiple outcomes of Raloxifene evaluation clinical trial. J. Clin. Endocrinol. Metab. 86:1212-1221.

13. Malabanan, A., Veronikis, I.E., and Holick, M.F. 1998. Redefining vitamin D insufficiency. Lancet. 351:805-806.

14. DeLuca, H.F., and Cantorna, M.T. 2001. Vitamin D: its role and uses in immunology. FASEB J. 15:2579-2585

15. Polek, T.C., and Weigel, N.L. 2002. Vitamin D in prostate cancer. J. Androl. 23:9-17.

16. Li, Y., et al. 2002. 1,25-dihydroxyvitamin $\mathrm{D}_{3}$ is a negative endocrine regulator of the renin-angiotensin system. J. Clin. Invest. 110:229-238. doi:10.1172/ JCI200215219.

17. Mathieu, C., Waer, M., Laureys, J., Rutgeerts, O., and Bouillon, R. 1994. Prevention of autoimmune diabetes in NOD mice by 1,25 dihydroxyvitamin $\mathrm{D}_{3}$. Diabetologia. 37:552-558.

18. McGrath, J. 2001. Does 'imprinting' with low prenatal vitamin $\mathrm{D}$ contribute to the risk of various adult disorders? Med. Hypotheses. 56:367-371.

19. Schwartz, G.G., Whitlatch, L.W., Chen, T.C., Lokeshwar, B.L., and Holick, M.F. 1998. Human prostate cells synthesize 1,25-dihydroxyvitamin D3 from 25-hydroxyvitamin D3. Cancer Epidemiol. Biomarkers Prev. 7:391-395.

20. Chen, T.C., and Holick, M.F. 2003. Vitamin D and prostate cancer prevention and treatment. Trends Endocrinol. Metab. 14:423-430. 